\title{
Behaviour change: Is human interaction the nub of the issue?
}

Someone I know recounted a recent visit to a physiotherapist after many months of putting up with a painful shoulder brought on by movements that required arm abduction. He seemed somewhat bemused by the set of exercises he had been given to do three times per day, as he did not understand what they were about or how they would help him get rid of his pain. He said that he had maintained the exercises for "about a day" - but also mentioned that he felt too guilty to go back to the physiotherapist for further advice.

I have been reflecting on this exchange in light of my recent attendance at the 2019 World Confederation for Physical Therapy (WCPT) Congress in Geneva. This was not my first attendance at a WCPT Congress and, as with previous congresses, I found it was an inspirational experience. I truly felt part of our global body of physiotherapists. It was an opportunity to interact at a personal level with old and new colleagues, to share ideas and experiences, and to look at things in different ways through the eyes of physiotherapists who work in a different context to New Zealand. I also felt proud to be able to contribute to our profession.

One of the discussion sessions at WCPT was about behaviour change in physiotherapy. This session proved to be personally rewarding and satisfying because of how attendees engaged with the topic. Together we discussed and debated the use, meaning and inferences behind words such as "compliance" and "adherence". "Compliance" suggests that a patient will comply with the command of the physiotherapist, while "adherence" suggests that patients will "stick fast" to the provided rehabilitation programme. We came to realise that both of these words imply that, as physiotherapists, we are using our own perspective and expertise to prescribe what we consider to be best for a patient.

Many attendees at the session acknowledged and spoke of how difficult and challenging it is to change patients' behaviour. Because the theories underpinning behaviour change originated in the domain of psychology (see the reference list for reading pertaining to behaviour change theory and practice), some of the audience even questioned whether behaviour change is therefore "out of scope" for physiotherapists. Nevertheless, the session's attendees also recognised that behaviour change would require interactions between patient and therapist that facilitated and supported the development of self-efficacy and self-determination by the patient, and that allowed the patient choice and control. Largely, the feeling in the audience was that behaviour change is an important aspect for successful rehabilitation, but also that knowledge and understanding of strategies to achieve behaviour change seem complex and overwhelming.

So how can we address this? There is an increasing body of literature within physiotherapy and rehabilitation science which identifies that healthful and helpful behaviours develop as a result of perceptions arising from human interactions. Is it, therefore, the importance of human interaction that physiotherapists should focus on first? Do we need to pay more attention to providing patients with the space and opportunity to identify and choose ways to incorporate health-enhancing movement into their daily activities - movement (or exercise or physical activity) that would make sense to them and that they would be able to sustain? Surely, if patients understood better why they are doing what they do and how this would be helpful in their rehabilitation journey, would they not be much more likely to "comply" with their own "prescription" of such movement or exercise?

Could physiotherapists pay more attention to allowing and enabling patients to find their preferred way through the rehabilitation process by discovering - and then taking into account - their "place and space" ? For example, if the gentleman referred to earlier had understood that he could have been "exercising" by paying attention to, and correcting, the postural set of his injured shoulder while ballroom dancing (his preferred recreational activity) instead of feeling guilty that he had not complied with instructions to do the designated set of exercises three times daily, then this would have opened up not only a successful pathway to rehabilitation, but also an open and collaborative dialogue with the physiotherapist.

Perhaps the question posed by an audience member is the nub of the issue: Was it the patient's or the physiotherapist's interaction that needed to change?

Ngā mihi,

Hilda Mulligan BSc (Physio), MHealSc, PhD

Centre for Health, Activity, and Rehabilitation Research, School of Physiotherapy, University of Otago, Dunedin, New Zealand

\section{REFERENCES (selected, there are many more)}

Bandura, A. (1977). Self-efficacy: Toward a unifying theory of behavioral change. Psychological Review, 84(2), 191-215. https://doi. org/10.1037/0033-295X.84.2.191

Bandura, A. (1986). The explanatory and predictive scope of self-efficacy theory. Journal of Social and Clinical Psychology, 4, 359-373. https://doi. org/10.1521/jscp.1986.4.3.359

Deci, E. L. \& Ryan, R. M. (2008). Self-determination theory: A macrotheory of human motivation, development, and health. Canadian Psychology, 49(3), 182-185. https://doi.org/10.1037/a0012801

Hanlon, P., Gray, C. M., Chng, N. R., \& Mercer, S. W. (2019). Does SelfDetermination Theory help explain the impact of social prescribing? A qualitative analysis of patients' experiences of the Glasgow 'Deep-End' Community Links Worker Intervention. Chronic Illness. May 3 https://doi. org/10.1177/1742395319845427 [Epub ahead of print]

Kelly, M. P., \& Barker M. (2016). Why is changing health-related behaviour so difficult? Public Health, 136, 109-116. https://doi.org/10.1016/j. puhe.2016.03.030

Michie, S., van Stralen, M. M. \& West, R. (2011). The behaviour change wheel: A new method for characterising and designing behaviour change interventions. Implementation Science, 6, 42. https://doi. org/10.1186/1748-5908-6-42

Ryan, R. M., \& Deci, E. L. (2000). Self-determination theory and the facilitation of intrinsic motivation, social development, and wellbeing American Psychologist, 55(1), 68-78. https://doi.org/10.1037/0003066X.55.1.68

Ryan, R. M., Patrick, H., Deci, E. L., \& Williams, G. C. (2008). Facilitating health behaviour change and its maintenance: Interventions based on Self-determination Theory. The European Health Psychologist, 10(1), 2-5. Retrieved from: https://www.ehps.net/ehp/index.php/contents/article/view/ ehp.v10.i1.p2/32

Teixeira, P. J., Carraca, E. V., Markland, D., Silva, M. N., \& Ryan, R. M. (2012). Exercise, physical activity, and self-determination theory: A systematic review. International Journal of Behavioral Nutrition and Physical Activity, 9, 78. https://doi.org/10.1186/1479-5868-9-78 